\title{
Determination of a standard for physical structure requirement for Belgian Blue bulls*
}

\author{
S. De Campeneere', L.O. Fiems and D.L. De Brabander \\ Department of Animal Nutrition and Husbandry, Agricultural Research Centre \\ Scheldeweg 68, B-9090 Melle, Belgium
}

\begin{abstract}
Based on data originating from 6 experiments with 4 treatments of varying physical structure supply in each experiment, a standard for physical structure requirement was derived for Belgian Blue bulls. The data related to the growth- and finishing period $( \pm 340-660 \mathrm{~kg})$ of 306 doublemuscled bulls.

As a standard for minimal physical structure requirement $0.60 / \mathrm{kg}$ DM can be advised for total mixed rations, with pelleted concentrates. For non-pelleted concentrates (ground or unground) this standard can also be used, but for non-mixed rations a somewhat higher structural value should be aimed at.
\end{abstract}

KEY WORDS: physical structure requirement, beef bulls, animal performance

\section{INTRODUCTION}

Belgian Blue bulls are generally fed diets high in energy, with only marginal amounts of roughage. This combination of a fast fermentation with little secretion of saliva (only little roughage) can cause acidosis (Owens et al., 1998). For practice, the minimal structure requirement is important to be known. Until now, no physical structure standard for beef cattle has been derived from scientific studies.

For dairy cattle, De Brabander et al. (1999) introduced a physical structure evaluation system. It is based on research determining the physical structure value of numerous feedstuffs as well as the physical structure requirements of dairy cattle. The requirements were determined with trials in which the roughage part of the diet of Holstein cows decreased weekly until symptoms of a physical

\footnotetext{
* Supported by the Ministry of the Flemish Community, IWT

${ }^{1}$ Corresponding author: e-mail: s.decampeneere@clo.fgov.be
} 
structure deficiency appeared (mainly a decrease in milk fat content). According to the system the structure value (SV) of the diet for a standard cow (25 kg milk in $1^{\text {st }}-3^{\text {rd }}$ lactation) should at least amount to $1.0 / \mathrm{kg} \mathrm{DM}(0.9$ if the concentrate is given in at least 6 meals).

The SV's, as available in the system for dairy cattle (De Brabander et al., 1999), mainly depend on the characteristics of the feedstuffs and can therefore also be used for beef cattle. In order to determine the need for physical structure of beef cattle the long-term influence of feeding a certain SV on the performances (intake, growth, feed conversion), on the quality of the end product (carcass and meat quality) and on some health-parameters (histological damage of the ruminal wall, incidence of claw disorders) was investigated.

\section{MATERIAL AND METHODS}

The data, used to determine the physical structure need, relate to the growth and finishing period (340-660 kg) of 306 Belgian Blue double-muscled bulls and originate from 6 experiments with 4 treatments of differing physical structure supply (SV of the diets between $0.32-0.97 / \mathrm{kg} \mathrm{DM}$ ) in each treatment. All diets were based on concentrates and maize silage was fed as a roughage in varying proportions. For some treatments straw was available in the rack. All bulls were housed on wood shavings to avoid straw intake from the floor. The bulls were weighed at four-week intervals to monitor their growth. The SV's of the maize silages and the concentrates were estimated form the crude fibre content and from the neutral detergent fibre, the sugar and the undegradable and degradable starch content, respectively. Straw has a fixed SV of 4.3 per $\mathrm{kg}$ DM (De Brabander et al., 1999). Intake and feed conversion parameters are available for the different treatments. At slaughter, different carcass and meat quality parameters were determined as well as some parameters to assess possible damage of the ruminal wall or claw disorders.

The results of the 6 experiments made up a dataset from which the standard for physical structure requirement was derived. As these data originated from different experiments that were performed over different years, other factors apart from the SV caused a certain variation in the observed parameters (intake growth, feed conversion). Therefore, a correction was made for the following interfering factors: year, the type of ration, the form (ground, unground, pelleted) and composition of the concentrate and the feeding strategy (mixed or separate). To derive the standard from the dataset, a two-fase linear model (Koops and Grossman, 1993) was used to find a breaking point statistically. In this study, the breaking point was the SV beneath which a significant adverse effect was found on e.g., growth, feed conversion or health parameters. 


\section{RESULTS AND DISCUSSION}

The results of the 6 separate production experiments indicated that the SV has no important influence on the meat or carcass quality. The effects on the histological damage of the ruminal wall or the claws were not unambiguous, and therefore not useful to derive the physical structure standard. The SV significantly influenced growth, feed intake and feed conversion. Figure 1 shows the relation between the SV of the different treatments and the growth rate.

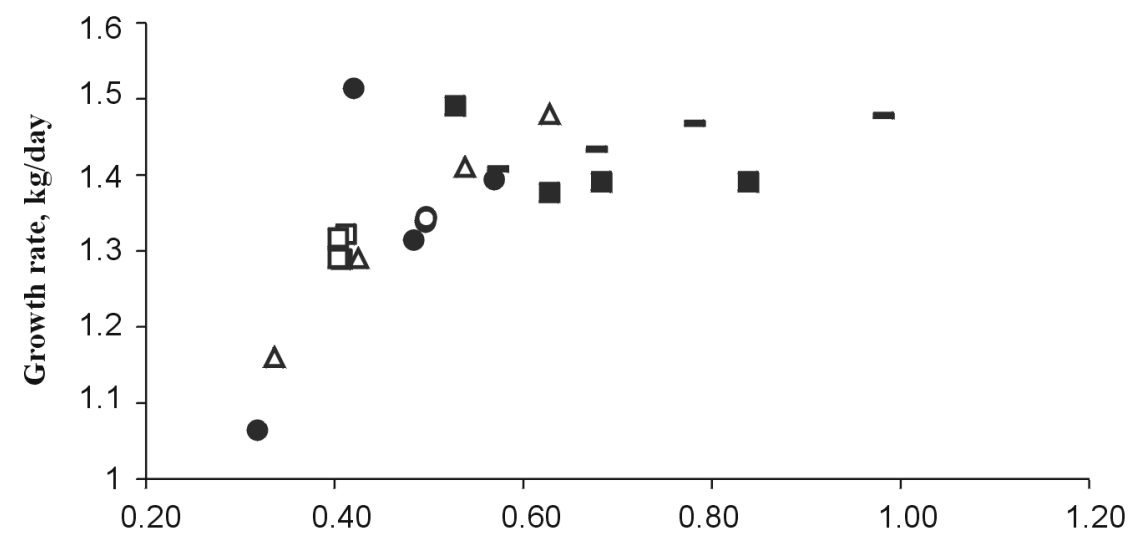

Structural value, SV/kg DM

Figure 1. Relation between the SV of the diet (/kg DM) and growth rate (kg/day) (different symbols for each experiment)

Applying the described model on the dataset for the different parameters that were affected by the SV resulted in a breakpoint for growth $(\mathrm{kg} /$ day), feed conversion (MJ NEF/ $\mathrm{kg}$ growth) and feed intake ( $\mathrm{kg} \mathrm{DM} /$ day) of $0.45,0.43$ and $0.58 / \mathrm{kg} \mathrm{DM}$, respectively. As feed conversion and growth are more important than feed intake (feed intake can decrease if growth and feed conversion remain favourable), $0.45 / \mathrm{kg}$ DM was adopted as breaking point for optimal performances.

The determined breaking point is a mean value for the dataset with a certain variation around that mean. Therefore, a safety margin is needed. From our dataset, that safety margin cannot be quantified, but previous research (De Brabander et al., 1999) with dairy cattle indicates that a margin of $30 \%$ should be applied to have a safe standard (aiming at a risk of 5\%). As such, for beef cattle ' $0.45 \times 1.30=0.585$ ' can be calculated, or a standard for physical structure requirement of ' $\mathrm{SV}=0.60 / \mathrm{kg} \mathrm{DM}$ ' is suggested. This standard is valid for mixed rations, with pelleted concentrates. 
Concentrates fed ground (not pelleted) or unground have a higher SV than the same concentrates fed as pellet. Therefore, the standard 0.60/kg DM is also adequate in these cases. For unmixed rations a somewhat higher standard is advised, however the size of that extra margin is dependent on the characteristics of the feedstuffs involved and can therefore not be quantified without extensive extra experiments. In dairy cattle, the surplus physical structure need due to unmixed rations was derived to be smaller than $0.1 / \mathrm{kg}$ DM.

From studies in which the roughage part decreased weekly until indications of physical structure deficiency were seen, De Campeneere et al. (2002) concluded that there is no effect of the conformation (double-muscled or not) on the critical roughage part. This suggests that the standard for physical structure is not only valid for double-muscled Belgian Blue bulls, but also for non-double-muscled ones and possibly for most beef breeds.

\section{CONCLUSIONS}

Based on existing SV's and feeding experiments with double-muscled bulls, a standard for physical structure requirement for beef cattle of $0.60 / \mathrm{kg} \mathrm{DM}$ can be advised for total mixed rations, with pelleted concentrates. For non-pelleted concentrates (ground or unground) this standard can also be used, but for nonmixed rations it is advised to aim at a somewhat higher SV.

\section{REFERENCES}

De Brabander D.L., De Boever J.L., Vanacker J.M., Boucqué Ch.V., Botterman S.M., 1999. Evaluation of physical structure in dairy cattle nutrition. In: P.C. Garnsworthy, J. Wiseman (Editors). Recent Advances in Animal Nutrition. 33 ${ }^{\text {rd }}$ Feed Manufacturers Conference, Nottingham (UK), pp. 111-145

De Campeneere S., Fiems L.O., De Boever J.L., Vanacker, J.M., 2002. Decreasing the roughage: concentrate ratio of a diet to determine the critical roughage part for beef cattle. Arch. Anim. Nutr. 56, 1-12

Koops W.J., Grossman M., 1993. Multiphasic allometry. Growth, Develop. Aging 57, 183-192

Owens F.N., Secrist D.S., Hill W.J., Gill D.R., 1998. Acidosis in cattle: a review. J. Anim. Sci. 76, 275-286 